\title{
POSITION OF THE BUD ON THE BUD STICK ON SUCCESS OF BUD GRAFT AND GROWTH Hevea brasiliensis (Muel Arg)
}

E.P.N. Udayakumara ${ }^{1}$ and P. Seneviratne ${ }^{2}$

\begin{abstract}
Budgrafting is currently the most popular method of propogation of rubber. The objective of this study was to determine the effect of the budwood on bud grafting success, sprouting and the scion growth. In the first part, the positional effect of individual buds was observed using brown budwood of two clones. There was no regular pattern in grafting success but, after a few successful grafts, there were one or two unsuccessful ones. Also, there were a certain percentage of dormant buds. Sprouting time also did not show any correlation with the position of the bud. The duration was different for two clones, 20 days for PB 217 and 60 days for clone $P B 255$.

The shoot originating height was tested in the second part of this study using green shoots. Some bush nurseries were pollarded at $50 \mathrm{~cm}$ and $180 \mathrm{~cm}$ of clones RRIC 100 and RRIC 121 . The differences were varied between the shoots of two original heights. However, the source bush trees were about 2-3 years old and therefore, these results are according to the expectation.
\end{abstract}

\section{INTRODUCTION}

Hevea brasiliensis Muell-Arg is an open pollinated crop, belongs to the family Euphorbiaceae. It is the quasi-exclusive source of natural rubber (NR). Hevea is widely cultivated in South East Asia. The main producers of NR are; Malaysia, Indonesia, Thailand, Sri Lanka and India. There is significant cultivation also in Liberia, Nigeria, Ivory Coast and Brazil. Other Asian and Latin American countries also produce NR (Peries O.S. and D.M. Fernando, 1983).

Rubber plants were introduced to Sri Lanka originated from seeds collected by Wickhan (1875) from Rio Tapaja, in Amazon. Seeds were germinated in Kew Gardens in UK and brought to Sri Lanka under the care of W. Chapan and planted in the Peradeniya Botanical Garden.

The rubber industry plays an important role in the economy of Sri Lanka. It's contribution to the export earnings was around Rs. 3,086 million in 1994 and rubber is ranked $8^{\text {th }}$ in the export earning of the country. Furthermore, the rubber industry creates employment for about 500,000 people (Central Bank of Sri
Lanka, 1994). The existence of about 166,000 ha of green forest is also an important factor. During the early period of the rubber industry, seeds were used for the establishment of new Hevea plantation.

With the realization of the large variation in growth and yield of seedling trees, vegetative propagation of clonal materials was introduced in to plantation practice. Budgrafting is currently the most popular method of plantation of Hevea. Preliminary trials were carried out on bud grafting in the 1920's and by 1936 the technique was widely practiced by the estate sector. By this method seeds of unknown parentage were collected, planted in the field or in a nursery and allowed to grow for 1-2 years. These plants were then budgrafted with using similar aged budwood and this technique is called "brown budding".

During the recent years there have been a number of developments in grafting technique "green budding" was first done by Hurow (1961) of the Department of Agriculture in North Borneo. The technique was improved and now green

${ }^{1}$ Department of Natural Resources, Faculty of Applied Science, Sabaragamuwa University of Sri Lanka, 
budding is carried out on stocks of 5-6 months. Even 2.5-4 months old seedlings can also be budgrafted by this technique and these plants called "young buddings". For green budding technique young shoots of about 6-12 weeks old are used to harvest bud patches.

Whatever the grafting technique used, once the grafting is successful, the stock plant should be removed for the grafted bud to grow. This is done normally after about 4-5 weeks of bud grafting. Sprouting of the grafted bud then takes place after 4 weeks and it takes more than 4 weeks to complete. This is a common problem especially in brown budded plants, which some times lead to uneven plant growth in the field.

\section{Objectives}

The aim of this experiment was to observe the position of the bud (on the bud stick) has an effect on time taken for sprouting and growth of the grafted scion.

\section{MATERIALS AND METHODS}

\section{Stock plants}

One year old seedlings with $2-2.5 \mathrm{~cm}$ in diameter were used as stocks for grafting.

\section{Budwood}

Clones of PB 217, PB 255, RRIC 100 and RRIC 121 raised as source bush (budwood) trees were used to harvest bud patches for this study.

Brown budwoods were harvested from clones PB 217, PB 255 whereas green budwoods were harvested from trees of RRIC 100 and RRIC 121. They were pollarded at two heights $(50 \mathrm{~cm}$ and 180 $\mathrm{cm})$ to produce shoots for harvesting green buds.

\section{Brown budding}

The age of the budwood was approximately 2-2.5 years. The bud stick of PB 217 was $4.5 \mathrm{~m}$ long and 49 bud patches could be harvested from each stick for grafted. The bud stick of PB 255 was
$4.09 \mathrm{~m}$ long and 51 bud patches were harvested from this. The size of the bud patch was about 3-4 $\mathrm{cm}$ long and $1.5-2 \mathrm{~cm}$ wide. Stem height ( $\mathrm{SH}$ ) (the height from the bud union to dormant bud) and stem diameter (SD), where the dormant bud is placed, were measured by using tape and vernier caliper respectively.

\section{Grafting success}

After 21 days from grafting polythene were removed and bark flap covering the bud patches were cut off. The bud patch was then scraped lightly with the point of a knife above and below the bud to check weather they were still green and alive.

\section{Green budding}

The age of the budwood for green budding was approximately $8-12$ weeks. The length of the bud sticks of RRIC 100 varied from 5 to $90 \mathrm{~cm}$ and 50 bud patches could be removed and used for grafting.

\section{Grafting success (green budding)}

Bud patches were examined 21 days from grafting. If the budpatch (green bud patch) was still green, then it was considered a success. After about 10 days of the first examination success was confirmed by checking the bud patches again.

\section{Raising plants in polybags}

The successful grafts were uprooted and planted in polybags, of $18 \mathrm{~cm} \times 45 \mathrm{~cm}$ made out of gauge 500 black ploythene tubing. Fertilizer was mixed with the soil at the rate of $50 \mathrm{~g}$ of NPK mixture and $100 \mathrm{~g}$ of Rock Phosphate per bag prior to filling. Plants were kept under moderate shade until the first whorl of leaves became hardened. Plants were sprayed with fungicides when leaf diseases detected. Watering was done when the required fertilizer was applied as recommended for a polybag plants, (Advisory Circular No 1992/01/ Fertilizer to rubber). 


\section{Assessment of growth}

Bud grafting success, sprouting time, branch angle; colour of shoots, shoot length and the diameter were recorded.

\section{RESULTS AND DISCUSSION}

\section{Effect of the position of the bud on the grafted plant}

This was done with brown budwood of clone PB 217 and PB 255. The effect of the position of the bud on bud grafting success, sprouting time, length of the scion and diameter of the scion etc. were observed and presented in Table 01

\section{Effect on the budgrafting success (Brown budding)}

The total number of usable buds and the grafting success as a percentage of total number of usable buds are presented in Table 01 .

The number of usable buds decreased with the increasing distance of budwood. As $1 \%$ of grafting success of each $1 \mathrm{~m}$ position is concerned, there is a decrease with the increase of the distance of budwood of PB 217. But no such pattern is observed with clone PB 255.

Figures 01 and 02 shows the pattern for two clones are different. However, these results are for single bud sticks and therefore these patterns may not represent the clone. Anyhow, it is observed in both Figures that after a few successful grafts, there are one or two unsuccessful ones.

The exact locations of the leaf whorls were not measured, in the bud sticks used, but this was measured for the two clones. The mean locations of leaf whorls are marked ' $\mathrm{o}$ ' the $\mathrm{x}$-axis.

Table 01. Percentage bud grafting success in each length for clone PB 217 and PB 255.

\begin{tabular}{lcccc}
\hline Length & \multicolumn{2}{c}{ PB 217 } & \multicolumn{2}{c}{ PB 255 } \\
$(\mathrm{cm})$ & $\begin{array}{l}\text { Total number of } \\
\text { usable buds }\end{array}$ & $\begin{array}{l}\text { Success } \\
\%\end{array}$ & $\begin{array}{l}\text { Total number of } \\
\text { usable buds }\end{array}$ & Success \% \\
\hline $0-100$ & 13 & 61 & 15 & 40 \\
$101-200$ & 12 & 58 & 15 & 15 \\
$201-300$ & 12 & 58 & 10 & 60 \\
$301-400$ & 4 & 50 & 8 & 60 \\
\hline
\end{tabular}




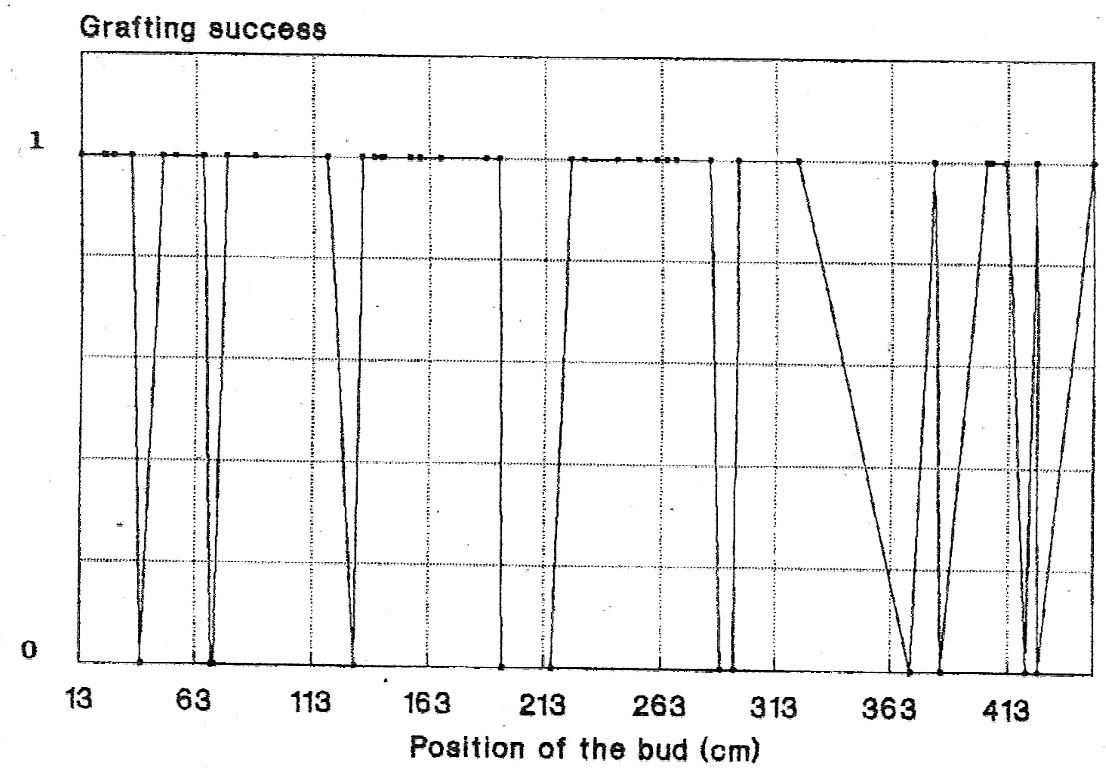

Figure 01. Percentage bud grafting success for clone PB 217

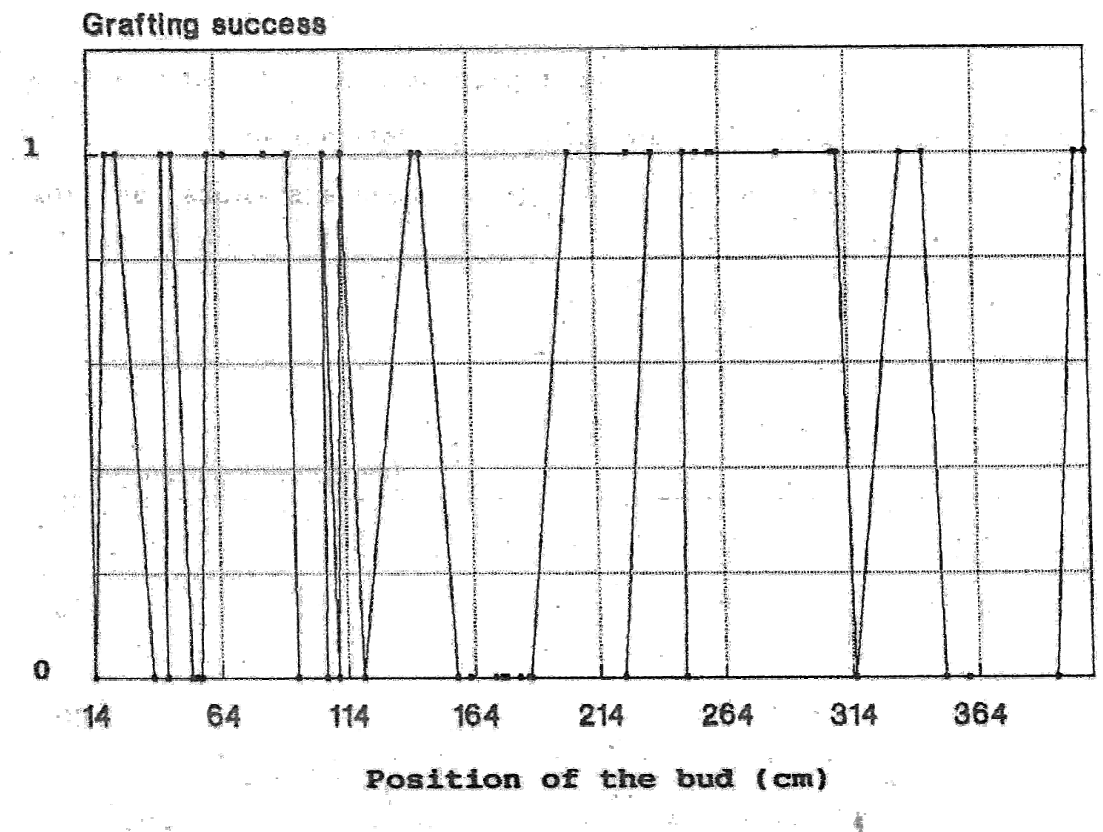

Figure 02. Percentage bud grafting success for clone PB 255 


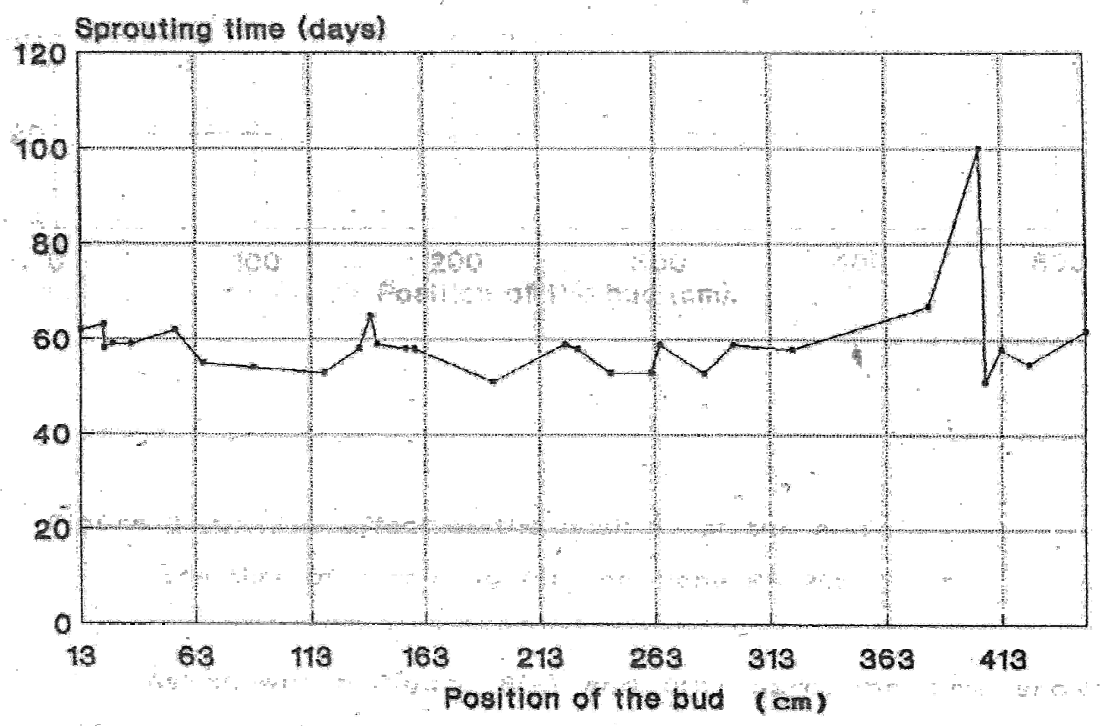

Figure 03. The effect of the position of the bud on the time of sprouting for the clone PB 217.

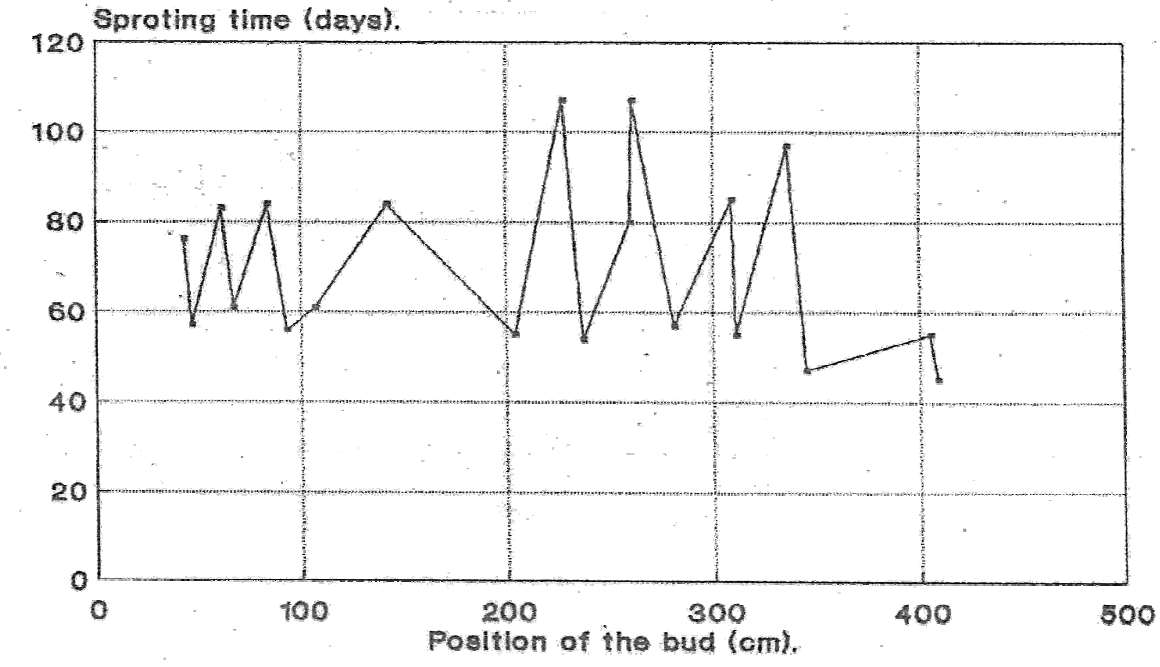

Figure 04. The effect of the position of the bud on the time of sprouting for the clone PB 255. 


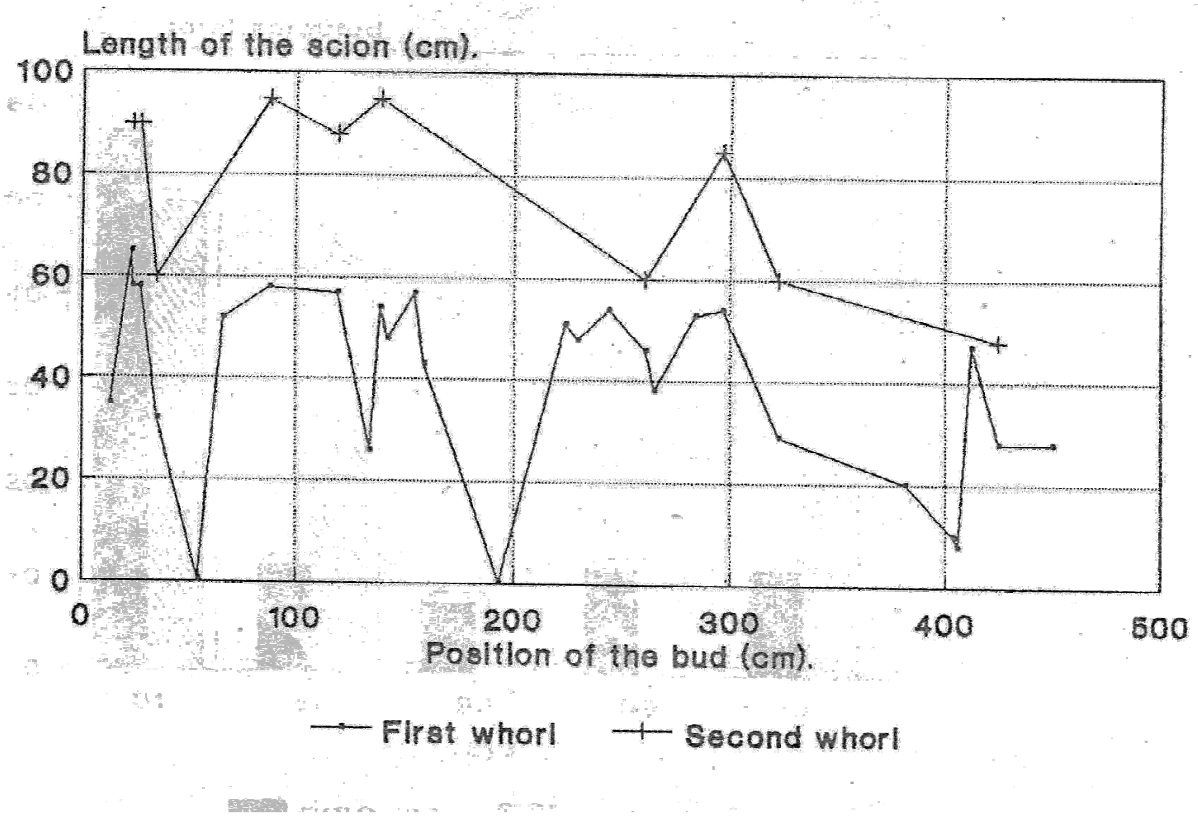

Figure 05. The effect of the position of the bud on the length of the scion (after 5weeks) at first whorl and $2^{\text {nd }}$ whorl (after 5weeks) for the clone PB 217.

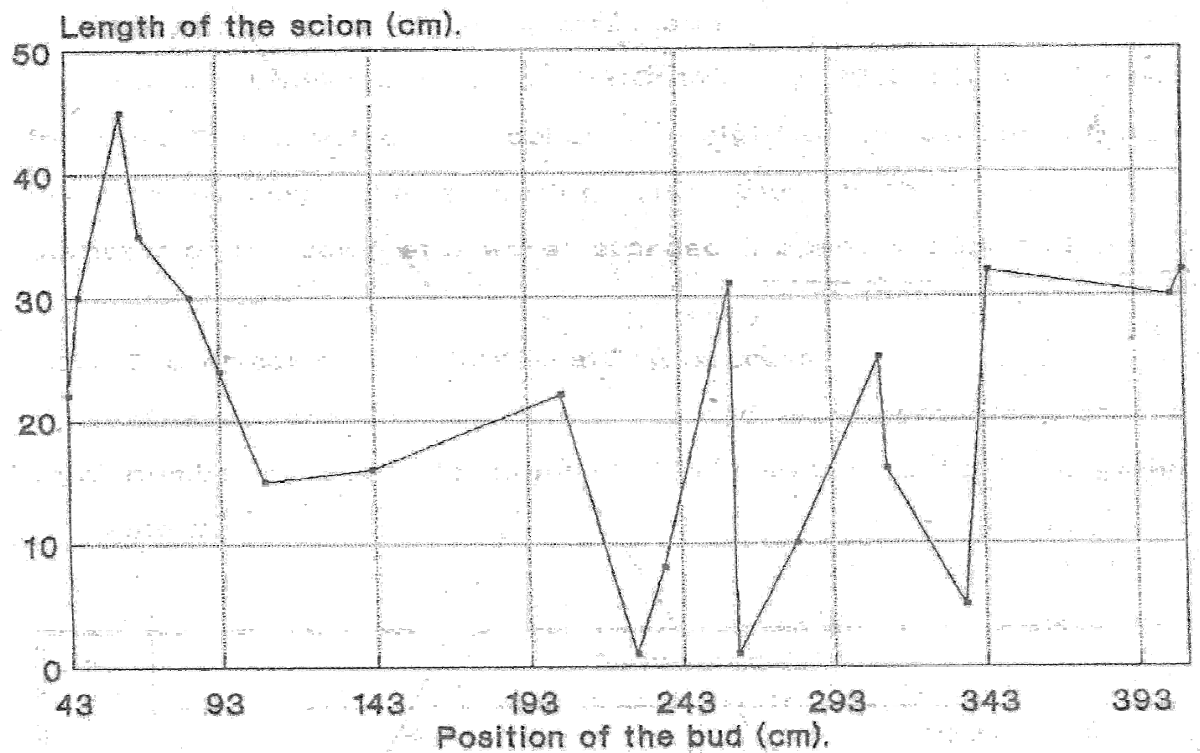

Figure 06. The effect of the position of the bud on the length of the scion at first whorl for the clone PB 255. 


\section{The effect on the sprouting time}

The time taken to sprout was recorded for each plant and the results are shown in Figures 03 and 04.

As shown in Figure 03 and 04 sprouting time shows differences. With clone PB 217 , almost all plants have sprouted within 50 - 70 days (20 day period) where as those of PB 255; the period is longer i.e., from 50 - 110 days (60 day).

As shown in Figures 05 and 06 length of the scions varies with the position of the bud. However, there is no regular pattern. Some buds did not sprout more than $3 \mathrm{~mm}$ even after 3 months.

After the development of the first whorl of leaves (after 4-5 weeks) there was a resting period of 6 weeks before the second whorl starts elongating.

The effect of the pollarded height of the sources bush plant on the performance of the grafted bud

Green budwood of clone PRIC 100 and PRIC 121 were used for this. The effect of the pollarded height on percentage of bud grafting success, the sprouting time, the length of the scion, diameter of the scion etc. were recorded .

\section{The effect on the bud grafting success}

The budgrafting success presented as a percentage of the total number of buds, in clone RRIC 100 and RRIC 121, are given in Table 02.

Bud grafting success shows differences for the shoots harvested from different height.

\section{The effect on the sprouting time The}

mean number of days and the duration taken to sprout was observed for the two types of shoots of clones RRIC 100 and RRIC 121 and results are shown in Table 03.

As shown in Table03, the mean number of days is in the range of 41-45 days for both clones. The duration of sprouting is slightly higher for shoots harvested at 180 $\mathrm{cm}$. The duration is in the range of 29-36 days, which is rather uniform.

Percentage sprouting in each week presented as a percentage of total sprouted are shown in Figure 07. From the total number of plants that sprouted, $58 \%$ and $50 \%$ grafting of RRIC 100 and RRIC 121 respectively, sprouted within the first week of the sprouting period.

Table 02. Percentage bud grafting success for shoot harvested from different heights of clone RRIC 100 and RRIC 121.

\begin{tabular}{lcccccc}
\hline Clone & \multicolumn{2}{c}{ Pollarded height } \\
& $\begin{array}{c}\text { Mean } \\
\text { Number } \\
\text { of shoot } \\
\text { produced }\end{array}$ & $\begin{array}{c}\text { Total } \\
\text { number } \\
\text { of usable } \\
\text { buds }\end{array}$ & $\begin{array}{l}\text { Success } \\
\%\end{array}$ & $\begin{array}{c}\text { Mean } \\
\text { number } \\
\text { of shoot } \\
\text { produced }\end{array}$ & $\begin{array}{c}\text { Total } \\
\text { number of } \\
\text { usable } \\
\text { buds }\end{array}$ & $\begin{array}{c}\text { Success } \\
\%\end{array}$ \\
\hline RRIC 100 & 1.5 & 17 & 78 & 4 & 18 & 66 \\
RRIC 121 & 2 & 16 & 78 & 3 & 26 & 75 \\
\hline
\end{tabular}


Table 03. The period and the mean number of days taken to sprout for the two clones

\begin{tabular}{lcclc}
\hline Clone & \multicolumn{3}{c}{ Pollarded height } & \multicolumn{2}{c}{$180 \mathrm{~cm}$} \\
& $\begin{array}{c}\text { Mean } \\
\text { number } \\
\text { of days }\end{array}$ & $\begin{array}{l}\text { Duration } \\
\text { (days) }\end{array}$ & \multicolumn{2}{c}{$\begin{array}{l}\text { Mean Duration } \\
\text { number } \\
\text { of days }\end{array}$} \\
\hline RRIC 100 & 41 & 29 & 41 & 34 \\
RRIC 121 & 45 & 31 & 43 & 36 \\
\hline
\end{tabular}

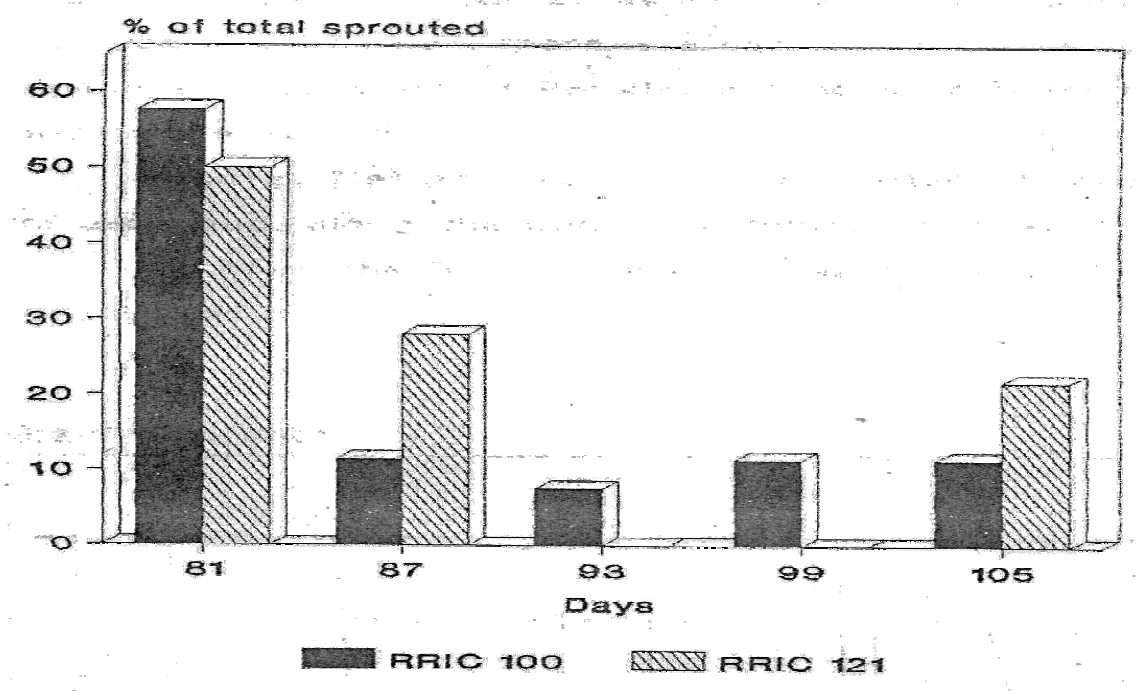

Figure 07. Percentage sprouting as percentage of total sprouted.

Table 04.The mean lengths of scion shoots of clones, RRIC 100 and RRIC 121

\begin{tabular}{ccc}
\hline Clone & \multicolumn{2}{c}{ Pollarded height } \\
$50 \mathrm{~cm}$ \\
$\begin{array}{c}\text { Mean length } \\
\text { of scion }(\mathrm{cm})\end{array}$ & $\begin{array}{c}180 \mathrm{~cm} \\
\text { Mean length } \\
\text { of scion }(\mathrm{cm})\end{array}$ \\
\hline $\begin{array}{c}\text { RRIC } \\
100\end{array}$ & $20 \pm 2.27$ & $23 \pm 2.43$ \\
RRIC & $23 \pm 2.56$ & $20 \pm 2.21$ \\
121 & & \\
\hline
\end{tabular}




\section{The effect on the length of the scion}

The mean length of the scion at first whorl for clones RRIC 100 RRIC 100 and RRIC 121 are shown in Table 04. Standard error mean values are also given with the mean values. The mean length at the first whorl is somewhat similar for the two clones and also for the shoot harvested at two different heights.

The primary aim of this study was to see the position of the bud on the grafting success, sprouting time and the growth of the plant.

This was tested in two ways. One was the positional effect of the buds of brown bud wood.. As the bud sticks were about $4 \mathrm{~m}$ long, the endogenous content of plant growth regulators etc; can be different which could directly or indirectly affect the budgrafting success and sprouting time etc

As far as budgrafting sucesssuccess is concerned, there was no pattern from one end to the other but however, after a few successful grafts there were one or two unsuccessful grafts. This was similar for both clones. Unfortunately, the exact location of leaf whorls would not be measured of the bud sticks used, the mean values of location of leaf whorls were 100 $\mathrm{cm}$ for clone PB 217 and $87 \mathrm{~cm}$ for clone PB 255.

The leaf whorls of the top half of the bud stick content leaves attached to them but only leaf scars were present on the bottom half.

The main idea of this experiment was to detect any causes attaching to the sprouting time. Normally, budded stumps start sprouting after 3-4 weeks of cut back. But, sometimes this period gets longer and this causes problem to the farmer when bare root budded stumps are planted in the field. Normally, the budded stumps are established in the field with the on set of the monsoon rains. Expecting the budded plant to sprout and establish in the field before the dry weather sets in. Majority of the plants will sprout in time, but a certain percentage remains dormant for too long and when they are exposed to dry weather very often they fail the establishment. Even in the present study. There were 4 percentages of buds, which remained dormant throughout the period, i.e. 5 months.

Further the duration of the sprouting seems to be related to the clones. The two clones used for the present study showed different. As shown in Figures 03 and 04 the duration for PB 217 and PB 255 were 20 and 60 days respectively.

In the second part of the study, the bud sticks originated from two heights, i.e. 180 $\mathrm{cm}$ and $50 \mathrm{~cm}$ were tested. In fact through the source bush plants were pollarded at $180 \mathrm{~cm}$ and $50 \mathrm{~cm}$, axillary shoots originated within $15-20 \mathrm{~cm}$ are below the cut back position. Here also, the bud grafting success, sprouting time, scion growth etc., were looked at. There were differences, but they were not statistically viable. In fact, the source bush trees were about 2-3 years old and therefore, factors related to juvenility and maturity or the phase change may not be important as Hevea trees below 5 years are in the juvenile phase. Results would have been different if the stock plants were more than 6-7 years old.

The buds used for this experiment were harvested from 1-1.5feet long green shoots. The duration of sprouting for RRIC 100 and RRIC 121 were much shorter (29-36) than that of PB 217 and PB 255 (20-60 days), which were $4 \mathrm{~m}$ long brown bud sticks. However, as the clones are different, whether this is related to the type or the age of bud wood or the clone is not clear.

The differences in sprouting times for "scale" and "axillary" buds have been reported earlier for both brown budding, (Samaranayaka and Gunaratne, 1977) and young budding (Seneviratne, 1995). Templeton and Shepherd (1967) observed that when the associated leaf, was removed immediately before green 
budding, leaf buds (axillary buds) emerged faster than when the associated leaf, was removed immediately before green budding, 'leaf buds' (axillary buds) emerged faster than when the associated leaf had been removed earlier. It has been suggested that growth substances produced by the associated leaf as a possible cause of the early emergence of these buds. In the present study only scale buds were used from both brown and green bud sticks.

Normally, shorter the duration of sprouting, the better the uniformity of the plantation. However, differences of even 2-3 weeks are generally decreases as the plants grow, especially for species like rubber which shows periodic growth.

\section{REFERENCES}

Advisory Circular (1992/01) - Fertilizer to Rubber, RRISL.

Central Bank of Sri Lanka (1992) - Annual Report. RRISL.

Peries O.S. and D.M.Fernando(1983). A Hand Book of Rubber Culture and Processing, RRISL.

Samaranayake, C. and R.B. Gunaratne, (1977). The use of leaf buds and 'scale buds' in the vegetation propergation of Hevea, Journal of RRISL, pp.19-21.

Seneviratne P. (1995). Bulletin of RRISL.

Templeton J.K. and R. Shepherd (1967). Some Technical Aspects of Green Budding, Bulletin RRIM, vol.92: pp. 190-197. 
